\title{
Conflictos socioambientales asociados al cambio en el metabolismo urbano: cantón Rumiñahui-Ecuador
}

\author{
Socio-environmental conflicts associated with the change in urban metabolism: \\ Rumiñahui -Ecuador

\section{Conflitos socioambientais associados à mudança no metabolismo urbano: cantão de Rumiñahui-Equador}

\author{
- Andrea Rodríguez-Guerra \\ andre.rodriguez.255@gmail.com \\ ORCID: 0000-0002-6230-5710 \\ Instituto Tecnológico Universitario
Cordillera, Quito-Ecuador
}

\author{
- Marcia Espinel-Ortíz \\ marci.espinel@gmail.com \\ ORCID: 0000-0002-0610-1510 \\ Facultad Latinoamericana de Estudios
Sociales, Quito-Ecuador
}

Artículo recibido 28 de octubre 2020 / Arbitrado y aceptado 19 de noviembre 2020 / Publicado 04 de enero 2021

RESUMEN

La parroquia periurbana de Sangolquí del cantón Rumiñahui-Ecuador, es un ejemplo de la transformación entre la ciudad y el campo. La migración de habitantes hacia las ciudades $y$ viceversa, ha modificado el uso de la energía y los materiales disponibles. Las prácticas agrícolas y ganaderas se han transformado $\mathrm{y}$ han producidos conflictos socioambientales. La investigación tuvo como objetivo analizar los cambios de flujos de materiales y energía; es decir, metabolismos rural, urbano e industrial del sector y su interacción. A través del análisis flujo/fondo de los usos del tiempo y la tierra, y métodos cualitativos y cuantitativos, se obtuvo una visión integral del metabolismo del sector. La interacción urbano/industrial con la zona periurbana, genera desplazamientos humanos, y acentúa la competencia por los recursos naturales entre metabolismos. Esto implica cambios en la cultura agrícola y una degradación ambiental que condiciona el uso de recursos como el agua y el suelo

Palabras clave: Metabolismo industrial; conflictos socioambientales; ecosistema urbano
ABSTRACT

RESUMO
The peri-urban parish of Sangolquí in Rumiñahui-Ecuador is an example of the transformation between the city and the countryside. The migration of inhabitants to cities and vice versa has modified the use of energy and available materials. Agricultural and livestock practices have been transformed and have produced socio-environmental conflicts. The research aimed to analyze the changes of material and energy flows; that is, rural, urban and industrial metabolisms of the sector and their interaction. Through the flow/background analysis of the uses of time and land, and qualitative and quantitative methods, a comprehensive view of the metabolism of the sector was obtained. The urban/industrial interaction with the peri-urban area, generates human displacements, and accentuates the competition for natural resources between metabolisms. This implies changes in agricultural culture and environmental degradation that conditions the use of resources such as water and soil.

Key words: Industrial metabolism; socio-environmental conflicts; urban ecosystem
A paróquia periurbana de Sangolquí no cantão Rumiñahui-Equador é um exemplo da transformação entre a cidade e o campo. A migração de habitantes para as cidades e vice-versa, modificou o uso da energia e dos materiais disponíveis. As práticas agrícolas e pecuárias se transformaram e geraram conflitos socioambientais. $\mathrm{O}$ objetivo da pesquisa foi analisar as mudanças no fluxo de materiais e energia; isto é, os metabolismos rural, urbano e industrial do setor e sua interação. Por meio da análise de fluxo / background dos usos do tempo e do solo, e de métodos qualitativos e quantitativos, obteve-se uma visão abrangente do metabolismo do setor. A interação urbana / industrial com a área periurbana, gera deslocamentos humanos, e acentua a competição por recursos naturais entre metabolismos. Isso implica em mudanças na cultura agrícola e na degradação ambiental que condiciona o uso de recursos como a água e o solo

Palavras-chave: Metabolismo industrial; conflitos socioambientais; ecossistema urbano 


\section{INTRODUCCIÓN}

El crecimiento poblacional en zonas periurbanas transforma el paisaje original y uso del suelo y así como, el uso de recursos y energía que se encuentran disponibles en el territorio (1), describe que la urbanización es un proceso de des-territorialización y reterritorialización en donde los flujos metabólicos están organizados bajo conductos sociales y físicos a los cuales llama "vehículos metabólicos". Este factor hace que la antropización, consecuencia del desarrollo económico de las sociedades deprede el territorio "natural".

Dentro de este sistema, el estado juega un papel clave en el proceso de regulación y planificación del territorio, a través del diseño de planes o proyectos urbanos. Dichos planes no siempre consideran la conservación del entorno ambiental ni la participación social. Es así que afirma que las actividades humanas en el proceso de urbanización son la forma de dominación más irreversible sobre la tierra (2). Los cambios en ambiente y el resultado de este proceso van desde la transformación de la cobertura vegetal, sistemas hídricos, clima, biogeografía del territorio y subsistemas sociales asociados a este entorno.

El cambio del uso de suelo de agrícola a industrial o a urbano obliga a las sociedades a encontrar nuevas fuentes de subsistencia. De ahí que el metabolismo urbano es más acelerado que el rural, y se impacta mayormente de las externalidades derivadas de las actividades urbanas.

La organización ecosistémica incluye la relación entre la comunidad y los recursos que tiene disponibles. El equilibrio de esta relación depende directamente de la forma en la que la comunidad use y mantenga una armonía entre lo cultural, lo productivo, lo ambiental y lo social.

De esta forma, los cambios en la estructura original del territorio generan conflictos tanto sociales como ambientales. La excesiva construcción de urbanizaciones, edificios en zonas rurales implica una explosión demográfica en espacios donde la actividad original era la agrícola o ganadera. Las necesidades de consumo de la población se incrementan con la aparición de infraestructuras. Muchas actividades y servicios se desplazan y ocupan territorios más lejanos de la mancha urbana; y poco a poco se evidencia un cambio del uso del suelo e implantación de sistemas de obras públicas, como el alcantarillado, que generalmente se descarga en un curso de agua que afecta completamente a la bioquímica y ciclo natural del recurso hídrico. Adicionalmente, en el área rural, el aumento poblacional repercute en un cambio del estilo de vida de la población y de sus actividades económicas en donde se reemplaza lo agrícola y ganadero por lo industrial y de servicios.

Hay estudio que describen los conflictos resultantes de la migración de poblaciones de campo hacia las ciudades $(3,4)$. Además, realiza reflexiones sobre el campo y la ciudad. Este cambio, sumado a la falta de normativa en el tema de planificación urbana, promueve la expansión de barrios periféricos que desencadenan conflictos socioambientales y competición por los recursos en sectores económicos y entre actores sociales. (5).

El enfoque de la ecología política, permite conocer y analizar la relación entre el metabolismo urbano e industrial con los 
conflictos de zonas rurales de las ciudades (68).

América Latina es la zona más urbanizada donde el $81 \%$ de la población vive en las ciudades $(9,10)$. Este aumento de la densidad poblacional afecta a la cantidad de descargas domésticas hacia las cuencas hídricas y cantidad de residuos generados, es decir a la capacidad de carga del sistema. La contaminación del agua y del suelo es la consecuencia directa de este proceso.

Por otro lado, el territorio periférico de las ciudades se convierte en una "nueva ruralidad" donde surge un cambio estructural en los procesos originales del suelo y ambiente (11); $\mathrm{y}$ es en donde se ubican las zonas periurbanas en la actualidad donde la ocupación del suelo continúa con su función agrícola y ganadera.

Las nuevas ruralidades llegan a contener en sus territorios una pluriactividad económica; es decir, se convierten en mosaicos de actividades con matices urbanos que resultan atractivos para la migración de la población interesada en salir del hipercentro de una ciudad. El desarrollo de la industria y su crecimiento generan también impactos ambientales en su ciclo de actividades que, muchas veces, afectan directamente a los sectores aledaños. La industria utiliza tanto materia como energía para mantener su producción en masa; es así que, en su proceso este sector productivo, de igual manera, genera contaminación atmosférica, hídrica y producción excesiva de residuos sólidos cuya disposición no siempre es la adecuada conforme la normativa vigente. Varios autores, describen estudios sobre conflictos socioambientales resultantes de la industrialización en las ciudades (12-15).
Así como en otros sitios de Latinoamérica, el cantón Rumiñahui, vecino del Distrito Metropolitano de Quito-Ecuador, específicamente de las parroquias rurales de este, se ve afectado por la migración de la población quiteña al campo. El incremento de oferta y la demanda de servicios generan un incremento en la contaminación ambiental, especialmente a la disposición de descargas líquidas a los cuerpos de agua dulce del cantón, tanto de carácter industrial como doméstico. Esta situación ha ocasionado frecuentes conflictos sociales en la zona por lo que es necesario realizar estudios sobre los flujos de energía y recursos en áreas para poder generar políticas públicas que no impacten al ambiente y a la sociedad. Los análisis de metabolismo urbano constituyen en la actualidad una herramienta valiosa para poder tener información sobre los recursos y materiales de una zona específica.

El objetivo del artículo es describir la situación metabólica del territorio, representada por los flujos de materia y energía, y los cambios en el metabolismo rural, urbano e industrial del sector de la parroquia Sangolquí, cantón Rumiñahui, provincia de Pichincha, Ecuador y su interacción con la población del territorio.

\section{MATERIALES Y MÉTODOS}

La unidad de análisis fue el cantón Rumiñahui, uno de los 8 cantones de la provincia de Pichincha ubicada en el centro norte del Ecuador. El cantón tiene aproximadamente 85852 habitantes según el censo poblacional realizado en el 2010 (Plan de Desarrollo y Ordenamiento Territorial de Rumiñahui 2012-2015) de aquí en adelante 
POT de Rumiñahui. (16). La parroquia de Sangolquí tiene un área de 50,42 km2, su población es de 58254 habitantes y su densidad poblacional aproximada es de 1155,37 habitantes/km2. (17). La mayoría de industrias $(53,54 \%)$, se ubican en la cabecera cantonal de Sangolquí y el resto en las parroquias aledañas (Cotogchoa y San Rafael) (18). La Figura 1, muestra la ubicación de la zona de estudio.
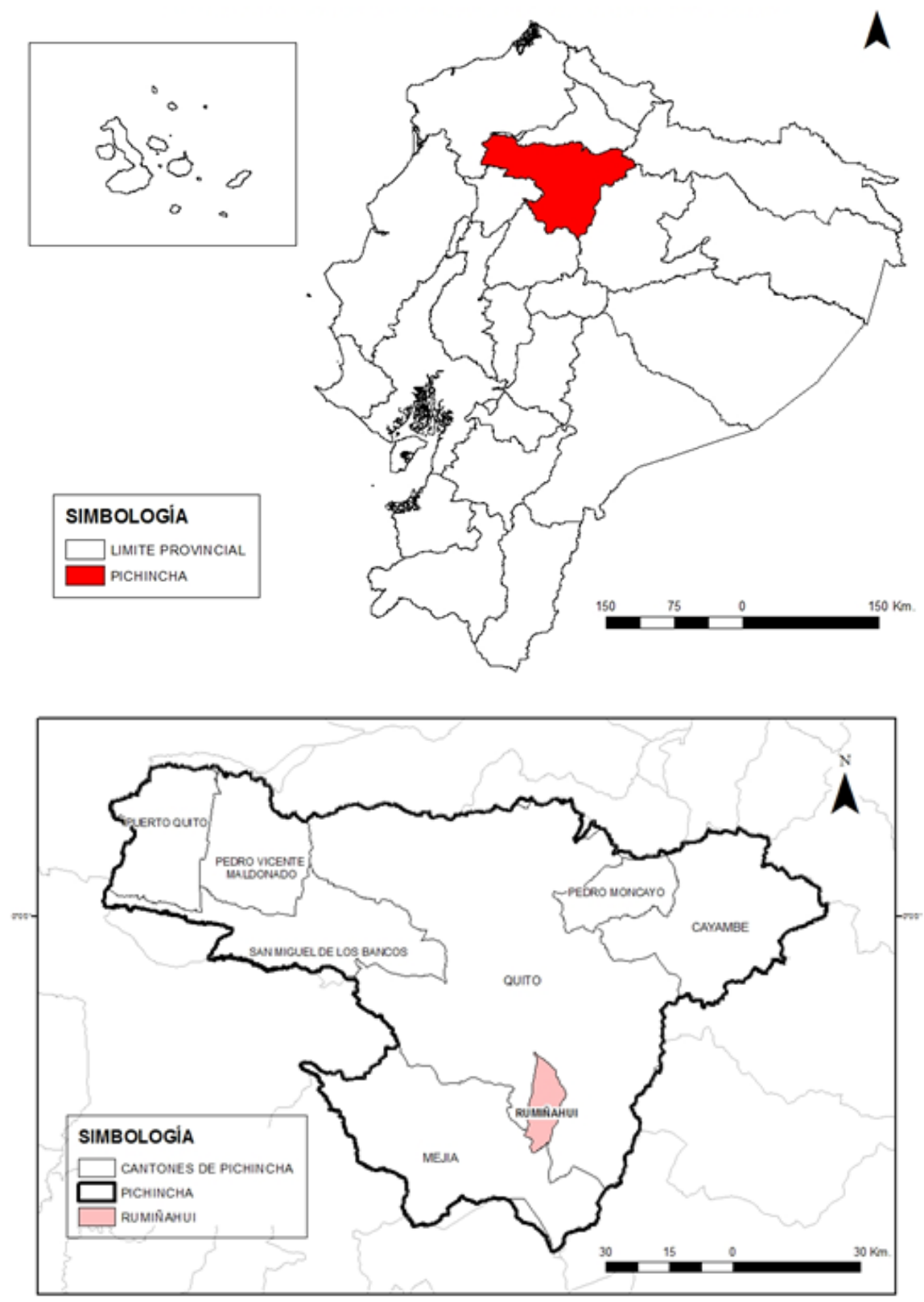

Figura 1. Mapas de la provincia y cantón. A. Imagen de la provincia de Pichincha en el mapa de Ecuador. B. Imagen del cantón Rumiñahui en el mapa de la provincia. Fuente: Coberturas en formato GIS, obtenidas de la página web del Instituto Nacional de Estadísticas y Censos (19), Elaborado por: Ing. Verónica López.

Alfa, Revista de Investigación en Ciencias Agronómicas y Veterinarias Vol. 5, N ro. 13, Enero - abril 2021 
La recolección de la información se llevó a cabo en tres fases:

Primero se levantó información sobre las características topográficas, económicas, ambientales y sociales de la parroquia de Sangolquí mediante la revisión del Plan de Desarrollo y ordenamiento Territorial PDOT 2012-2025 de Rumiñahui.

Posteriormente se realizó una división del territorio para delimitar la población y las actividades, productos y servicios que generan. Se establecieron escalas de análisis (dendrograma) para ubicar barrios, sectores y tipologías iniciales relacionadas con las actividades productivas a nivel rural e industrial. El Censo de Actividad Nacional Económico, así como del Censo de Población y Vivienda realizadas por el Instituto Nacional de Estadísticas y Censos (INEC) en el año 2010 sirvió como insumo para caracterizar a la población en análisis.
Se realizó el análisis integrado y multiescala del metabolismo social (MuSIASEM) (20- 22), que se aplica a distintas escalas geográficas, en un país o región (23). El análisis multiescalar permite establecer tipologías ( $n-1, n-2)$ en cada nivel que permiten comprobar la congruencia en las dimensiones de análisis y se puede desglosar una parte del sistema o las características del conjunto de datos $(21,24)$.

El nivel n-1 lo conforma el uso del área urbana, rural y la zona industrial. A través del mapa de la parroquia Sangolquí y la información de las entrevistas a miembros de la población, se ubicaron los conflictos y causas de los mismos.

A través de las agrupaciones se creó el nivel (n-2) que comprende información sobre trabajo pagado (tp), trabajo en casa ( $\mathrm{tc}$ ) y ocio (oc), para lo cual se generaron tipologías según el caso (Figura 2).

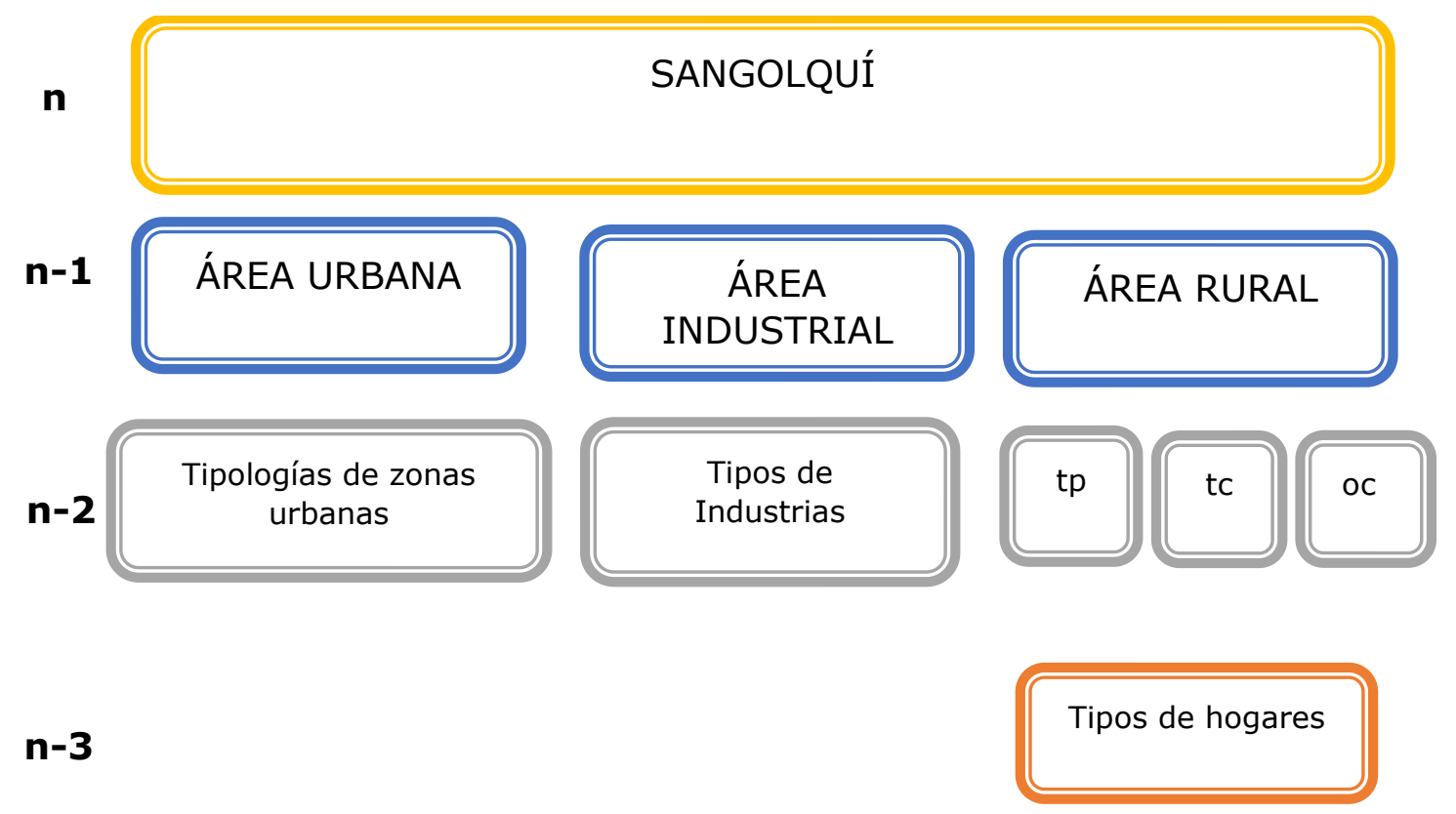

Figura 2. Niveles de análisis de la información en el estudio de metabolismo urbano. 
Se realizaron entrevistas para conocer la forma en la que la parroquia Sangolquí ha cambiado a lo largo del tiempo. Posteriormente, se realizó un sondeo para conocer los procesos o actividades productivas que realizan, la tasa de consumo de agua, tasa de generación de residuos sólidos. Además, se recolectó información sobre la apreciación de la gente para la gestión de residuos sólidos, líquidos de la industria para entender el sistema de producción y su proceso metabólico.

Se definieron cinco tipologías iniciales que corresponden a las actividades que realizan las personas en la zona rural o periférica de la parroquia basadas en el Plan de Desarrollo y Ordenamiento Territorial Rumiñahui 2012-2015 (Tabla 1).

Tabla 1. Tipologías iniciales para las actividades de la parroquia de Sangolquí, cantón Rumiñahui- Ecuador.

\begin{tabular}{|c|c|c|}
\hline TIPOLOGÍA & & DESCRIPCIÓN \\
\hline & VIVIENDA & $\begin{array}{r}\text { Se dedican únicamente a la administración de hogares, } \\
\text { poseen empleo y permanecen fuera de casa la mayor } \\
\text { parte del día. }\end{array}$ \\
\hline & CRIANZA DE ANIMALES & Tiene actividades ganaderas, de silvicultura o pesca. \\
\hline & AGRICULTURA & $\begin{array}{r}\text { La agricultura es la actividad económica principal, y la } \\
\text { que mantiene el hogar. }\end{array}$ \\
\hline & HUERTOS & $\begin{array}{r}\text { Se incluye esta actividad, en atención al tamaño del } \\
\text { predio, que en algunos casos es menor de } 500 \mathrm{~m} 2 \text {, por lo } \\
\text { que la agricultura como tal no se da y solo se mantienen } \\
\text { pequeños huertos. (información proporcionada en la } \\
\text { Dirección de Catastros del GADMUR) }\end{array}$ \\
\hline & NEGOCIOS & $\begin{array}{l}\text { Realizan una actividad económica que no se encuentra } \\
\text { relacionada con la agricultura o la crianza de animales. }\end{array}$ \\
\hline
\end{tabular}

Fuente: Basada en la información disponible dentro del Plan de Desarrollo y Ordenamiento Territorial de Rumiñahui 2012-2025, además de la información de los Censos de Actividades Económicas y Población y Vivienda realizada por el INEC en el 2010 (16).

Se describieron indicadores, con los cuales se formularon las preguntas de la encuesta, mismas que fueron semiestructuradas, y aplicada en la muestra de los sectores rurales o periurbanos, principalmente el industrial (Tabla 2). 
Tabla 2. Indicadores y preguntas de cuestionario a la población de estudio.

\begin{tabular}{|c|c|c|c|}
\hline OBJETIVO & DIMENSIÓN & INDICADOR & $\begin{array}{c}\text { PREGUNTA DE } \\
\text { ENCUESTA/ENTREVISTA } \\
\text { /OBSERVACIÓN }\end{array}$ \\
\hline $\begin{array}{l}\text { Estudiar los } \\
\text { cambios en los } \\
\text { procesos }\end{array}$ & Tiempo & $\begin{array}{l}\% \text { de tiempo dedicado a } \\
\text { actividades en el hogar }\end{array}$ & $\begin{array}{l}\text { ¿Cuántas horas dedica al trabajo } \\
\text { en el hogar? }\end{array}$ \\
\hline \multirow{4}{*}{$\begin{array}{l}\text { metabólicos que } \\
\text { generan } \\
\text { conflictos } \\
\text { socioambientales } \\
\text { en la parroquia } \\
\text { de Sangolquí. }\end{array}$} & & $\begin{array}{l}\% \text { de tiempo dedicado al } \\
\text { trabajo pagado }\end{array}$ & $\begin{array}{l}\text { ¿Cuántas horas dedica al trabajo } \\
\text { fuera de casa? }\end{array}$ \\
\hline & Superficie & $\begin{array}{l}\text { Cantidad de área utilizada } \\
{\text { en } \mathrm{m}^{2}}\end{array}$ & $\begin{array}{l}\text { ¿Cuál es el área de su terreno? } \\
\text { ¿En } \mathrm{m}^{2} \text { o ha? }\end{array}$ \\
\hline & Crecimiento & $\begin{array}{l}\text { Existencia de conflictos } \\
\text { asociados al crecimiento } \\
\text { de la población }\end{array}$ & $\begin{array}{l}\text { ¿Existen conflictos asociados al } \\
\text { uso de suelo? }\end{array}$ \\
\hline & & & $\begin{array}{l}\text { ¿Qué empresas están } \\
\text { relacionadas con los conflictos? }\end{array}$ \\
\hline $\begin{array}{c}\text { Investigar sobre } \\
\text { el contexto } \\
\text { histórico-actual } \\
\text { de la }\end{array}$ & Superficie & $\begin{array}{l}\% \text { de incremento de la } \\
\text { superficie del territorio } \\
\text { urbano }\end{array}$ & $\begin{array}{l}\text { ¿Cuáles eran los límites urbanos } \\
\text { de la parroquia de Sangolquí? }\end{array}$ \\
\hline $\begin{array}{l}\text { planificación del } \\
\text { territorio en la } \\
\text { parroquia de } \\
\text { Sangolquí. }\end{array}$ & Población & $\begin{array}{l}\% \text { de incremento de la } \\
\text { población urbana }\end{array}$ & $\begin{array}{l}\text { ¿Cuántas personas habitaban la } \\
\text { parroquia urbana de Sangolquí? } \\
\text { ¿Cuántas la habitan ahora? }\end{array}$ \\
\hline \multirow{6}{*}{$\begin{array}{c}\text { Identificar el } \\
\text { metabolismo } \\
\text { vinculado al } \\
\text { cambio del uso } \\
\text { de suelo, tiempo } \\
\text { y agua de la } \\
\text { población de la } \\
\text { referida } \\
\text { parroquia }\end{array}$} & Tiempo & $\begin{array}{l}\% \text { de actividades que } \\
\text { realizan a diario }\end{array}$ & $\begin{array}{l}\text { ¿Qué actividades realiza en su } \\
\text { propiedad? }\end{array}$ \\
\hline & Población & $\begin{array}{l}\text { Costos de los insumos que } \\
\text { utilizan en las actividades }\end{array}$ & $\begin{array}{l}\text { ¿Para realizar sus actividades } \\
\text { qué insumos requiere? ¿Cuáles } \\
\text { son los costos? }\end{array}$ \\
\hline & & & $\begin{array}{l}\text { ¿Cuántos Kg de producto obtiene } \\
\text { al mes? }\end{array}$ \\
\hline & Agua & $\begin{array}{l}\text { Tasa de consumo de agua } \\
\text { en } \mathrm{m}^{3} / \mathrm{año}\end{array}$ & $\begin{array}{l}\text { ¿En qué actividades utiliza el } \\
\text { agua? ¿Cuántos } \mathrm{m}^{3} \mathrm{al} \text { mes? }\end{array}$ \\
\hline & & & $\begin{array}{l}\text { ¿De dónde proviene el agua que } \\
\text { consume? }\end{array}$ \\
\hline & & & $\begin{array}{l}\text { ¿A dónde va el agua que } \\
\text { consume? }\end{array}$ \\
\hline
\end{tabular}




\begin{tabular}{|c|c|c|c|}
\hline OBJETIVO & DIMENSIÓN & INDICADOR & $\begin{array}{c}\text { PREGUNTA DE } \\
\text { ENCUESTA/ENTREVISTA } \\
\text { /OBSERVACIÓN }\end{array}$ \\
\hline $\begin{array}{l}\text { Identificar el } \\
\text { metabolismo } \\
\text { vinculado al } \\
\text { cambio del uso } \\
\text { de suelo, tiempo } \\
\text { y agua de la } \\
\text { población de la } \\
\text { referida } \\
\text { parroquia }\end{array}$ & $\begin{array}{l}\text { Residuos } \\
\text { Sólidos }\end{array}$ & $\begin{array}{l}\text { Tasa de generación de } \\
\text { residuos sólidos Kg/año }\end{array}$ & $\begin{array}{l}\text { ¿Cuántas fundas de basura } \\
\text { genera a la semana? } \\
\text { ¿Qué hace con los residuos? }\end{array}$ \\
\hline $\begin{array}{l}\text { Realizar una } \\
\text { revisión de la } \\
\text { legislación } \\
\text { asociada con el } \\
\text { cambio en el uso } \\
\text { de suelo y } \\
\text { vinculados con la } \\
\text { expansión } \\
\text { urbana }\end{array}$ & Territorio & $\begin{array}{l}\text { Normativa actual que } \\
\text { contempla el cambio del } \\
\text { uso de suelo en el cantón. }\end{array}$ & $\begin{array}{l}\text { ¿Con qué instrumentos legales se } \\
\text { norma el uso de suelo dentro del } \\
\text { cantón? } \\
\text { ¿Cuáles son los criterios que } \\
\text { fueron utilizados para establecer } \\
\text { dicha normativa? }\end{array}$ \\
\hline
\end{tabular}

Se realizaron conversaciones informales con un grupo identificado previamente para concluir con el diseño de la encuesta a la muestra. La observación participante fue la técnica más importante del estudio ya que permitió analizar y levantar información del ambiente urbano, rural e industrial. Esta información sirvió para relacionar los resultados de las encuestas, entrevistas y documentos de información con los cambios en el entorno.

Las entrevistas fueron diseñadas $\mathrm{y}$ aplicadas a casos puntuales, y se utilizó únicamente en el sector urbano. Mediante este instrumento, se describió el cambio de uso del suelo de acuerdo a las actividades de la parroquia en algunos aspectos que se detallan a continuación: porcentaje de incremento en la superficie del territorio, aumento de la población urbana, modificaciones que este fenómeno ocasionó en la planificación y ordenamiento territorial del cantón y existencia de conflictos asociados a contaminación ambiental y modificación de costumbres de la parroquia. Cada entrevista fue documentada en audio con el permiso de la persona, fue transcrita y sistematizada en una base de análisis de contenidos.

Las encuestas semi-estructuradas se realizaron a población rural de Sangolquí. Se calculó una muestra representativa de la población usando la información disponible de la Dirección de catastros del Municipio de Rumiñahui. La encuesta tuvo preguntas de opción múltiple que facilitaron la recopilación de la información y su análisis. Se preguntaron aspectos sobre el uso del tiempo y el agua; además, se recopiló información sobre horas 
del día dedicadas al trabajo pagado, trabajo en casa, ocio y consumo calculado en dólares al mes. Finalmente, se incluyeron tres preguntas sobre conflictos identificados y la forma cómo la población veía los cambios en los componentes ambientales antes y después de su urbanización.

Para el sector industrial, se incluyeron preguntas sobre la cantidad de recursos usados por la empresa y residuos que generaba en su proceso productivo; adicionalmente, se colocó una pregunta sobre los conflictos que la industria percibe por el sector en el que se encuentra.

Se realizó análisis de contenido, con enfoque comparativo, para examinar la información y compararla con "núcleos temáticos" como lo describe (25). Posteriormente, se elaboró una red de contenidos de entrevistas y encuestas que permitieron determinar el estado de la parroquia, los conflictos ocasionados por el cambio de metabolismo.

Los datos de consumo de agua y generación de residuos sólidos fueron expresados en costos de consumo al mes y en número de fundas de basura a la semana, respectivamente. La información correspondiente al consumo de agua para consumo humano se obtuvo de la Dirección de agua potable y alcantarillado. Para el tema de los residuos se tomó como referencia la densidad promedio de los residuos a nivel rural que fue de $299,03 \mathrm{Kg} / \mathrm{m}^{3}$. Con este dato se pudo calcular el número de fundas a la semana y posteriormente la cantidad de bolsas resultantes al año.

Finalmente, se realizaron cálculos estadísticos descriptivos con la información (media, moda, mediana, desviación estándar) y tendencia de datos. Se calculó la normalidad de los datos en base a los valores promedios totales.

\section{RESULTADOS}

Se consideraron dos aspectos: el primero fue la planificación del territorio y el segundo los conflictos socioambientales producidos por la interacción entre las actividades industriales $\mathrm{y}$ el entorno (metobolismo urbano). La ubicación topográfica y las condiciones climáticas y geomórficas de Rumiñahui, originalmente pensado como territorio agrícola, en la actualidad lo hace muy atractivo para el asentamiento de las nuevas industrias $y$ también de nuevas urbanizaciones.

Según el POT de Rumiñahui el territorio se divide en tres categorías: urbana, de influencia inmediata y rural. Sangolquí, particularmente fue zona de influencia, pero en la actualidad es completamente urbana. Su estructura vial, transporte público y servicios están en expansión. Existe, únicamente un barrio de la zona, que tiene uso de suelo agrícola. Los habitantes de este sector mantienen un estilo de vida rural con actividades mixtas de agricultura y crianza de animales, a lo que se denominarán "nuevas ruralidades" (26).

El crecimiento urbano ha modificado el estilo de vida de los pobladores, es aquí donde confluyen los tres tipos de metabolismos: el urbano, el rural y el industrial. Existen otros espacios rurales (Salgado, San Fernando y Curipungo) que mantienen actividades mixtas entre comercio, servicios, agricultura y crianza de animales. Otro término que describe esta situación es lo que se llama, periurbano o rurbano.

Como resultado de las 64 encuestas a hogares, la población de profesión "ama de casa" fue del $37,5 \%$, luego la de albañil con el 
6,25\%, carpintero con el 4,69\% y mecánico con el $1,56 \%$.

Entre las actividades más comunes realizadas fuera del hogar están: comerciantes $4,69 \%$, conductores con $1,56 \%$, electricistas (1,56\%), empleadas domésticas $(7,81), \quad \mathrm{y}$ empleados públicos o privados (4,69\%). Solo el
$6,25 \%$ de personas que se dedican únicamente a la agricultura. La superficie de los terrenos oscila entre los $50 \mathrm{~m}^{2}$ y los $8000 \mathrm{~m}^{2}$. El área más común es 100,500 y $1200 \mathrm{~m}^{2}$. La tabla 3 describe las tipologías de actividades encontradas en Sangolquí.

Tabla 3. Tipologías existentes en base a la muestra de 64 hogares y porcentajes.

\begin{tabular}{lll}
\hline TIPOLOGÍA & DESCRIPCIÓN & PORCENTAJE \\
\hline
\end{tabular}

1. Vivienda únicamente

2. Crianza de animales y Huertos

3. Crianza de animales y Agricultura

4. Huertos únicamente

5. Solo Negocio

6. Negocio, Crianza de animales y Huertos

7. Negocio, Huertos y/o Agricultura

8. Crianza de Animales únicamente
Se usa el predio solo como domicilio, se asemeja a un departamento o casa a nivel urbano.

Existe la crianza de animales pequeños y que ocupan 18,75 un espacio reducido como cuyes, conejos y gallinas. Algunos son, en su mayoría utilizados para consumo propio, y se mantienen en pequeños huertos con cultivos intensivos de hortalizas y vegetales, que sirven para abastecer a los miembros de la familia.

Tienen crianza de animales (cuyes, conejos, cerdos y gallinas) que en su mayoría son para la venta. Se mantienen campos de agricultura, en especial de maíz y papa, mismos que son para la venta.

Los huertos son utilizados de forma intensiva, para consumo propio del hogar. Los cultivos más comunes son la cebolla, lechuga, col, rábanos, perejil, coliflor, etc.

Un negocio forma parte del predio donde se encuentra el hogar, o se encuentra cerca del mismo.

Adicionalmente al negocio (tiendas o carpinterías), mantienen actividades de crianza de animales y huertos dentro de sus predios principalmente para el autoconsumo.

Adicional al negocio, generan un ingreso mediante la agricultura, y consumen de los huertos.

En el predio tienen crianza de animales. Estos son animales menores como los conejos, cuyes y cerdos. Para el caso del ganado mayor, como las vacas, arriendan lugares extensos donde puedan pastar, donde los animales son llevados a pie. 
El 17,19\% de los hogares encuestados describen la tipología vivienda únicamente mientras que, el 10,94\% mantiene negocios en sus hogares.

En la zona rural, las actividades más comunes son la agricultura y la crianza de especies menores $(18,75 \%)$. EL $71,88 \%$ de los encuestados vinculan sus actividades con prácticas agrícolas y de crianza de animales.

Las aguas negras y grises residuales, son dispuestas en el sistema de alcantarillado o direccionados hacia el cuerpo de agua más cercano, situación que afecta la calidad del recurso hídrico, Los residuos sólidos que son dispuestos en estas áreas, en su mayoría corresponden a desechos orgánicos, mismos que de acuerdo a los resultados de las encuestas, suelen ser enterrados en los terrenos o quemados a cielo abierto, para después utilizar su ceniza como abono. Es así, que los desechos considerados inorgánicos son entregados al carro recolector.

Las tipologías uno, cinco y seis (Tabla 3) generan mayor cantidad de residuos sólidos que otras. Las actividades más relacionadas con la agricultura y la crianza de animales producen por lo general una mayor cantidad de residuos orgánicos, mismos que pueden ser aprovechados en sus terrenos o espacios verdes.

El negocio con mayor incidencia en la población es tienda de abarrotes, cuya actividad al igual que las otras genera residuos sólidos urbanos, cuyo tipo varía conforme el producto adquirido por el comprador. Por lo general, los residuos corresponden a botellas y bolsas plásticas, papel y cartón. En segundo lugar, se encuentra, la venta de empanadas y sastrería, que igualmente genera grandes cantidades de desechos, como tela, algodón, servilletas, fundas plásticas y envases desechables. La generación de desechos, que presenta esta tipología, supera a la registrada por los negocios (tipología 5) y la vivienda (tipología 1). (Tabla 4).

Tabla 4. Resultados de los flujos/fondos.

\begin{tabular}{|c|c|c|c|c|c|c|c|c|}
\hline Tipologías & $\begin{array}{l}\text { \% Tiempo } \\
\text { dedicado } \\
\text { al trabajo } \\
\text { pagado }\end{array}$ & $\begin{array}{l}\text { \% Tiempo } \\
\text { dedicado } \\
\text { al trabajo } \\
\text { en casa }\end{array}$ & $\begin{array}{c}\% \\
\text { Tiempo } \\
\text { dedicado } \\
\text { al ocio }\end{array}$ & $\begin{array}{l}\text { Miembros del } \\
\text { hogar } \\
\text { (promedio de } \\
\text { individuos) }\end{array}$ & $\begin{array}{c}\text { Tasa de } \\
\text { consumo } \\
\text { de agua por } \\
\text { tipología } \\
\text { (m3/año) }\end{array}$ & $\begin{array}{c}\text { Tasa generación } \\
\text { de residuos no } \\
\text { aprovechables } \\
\text { (kg/año) }\end{array}$ & $\begin{array}{c}\text { Territorio } \\
\text { utilizado } \\
\text { (m2) }\end{array}$ & $\begin{array}{c}\text { Cantidad } \\
\text { de } \\
\text { producto } \\
\text { por unidad } \\
\text { de área } \\
(\mathrm{kg} / \mathrm{m} 2)\end{array}$ \\
\hline Vivienda & $32,08 \%$ & $16,67 \%$ & $20,83 \%$ & 5,18 & 252,44 & 897,66 & 282,86 & 0,00 \\
\hline $\begin{array}{l}\text { Crianza y } \\
\text { huertos }\end{array}$ & $26,39 \%$ & $22,92 \%$ & $34,52 \%$ & 5,00 & 417,78 & 321,39 & 974,00 & 0,10 \\
\hline $\begin{array}{l}\text { Crianza y } \\
\text { agricultura }\end{array}$ & $28,13 \%$ & $23,44 \%$ & $13,54 \%$ & 6,33 & 313,58 & 675,55 & 2664,29 & 0,06 \\
\hline
\end{tabular}




\begin{tabular}{|c|c|c|c|c|c|c|c|c|}
\hline Tipologías & $\begin{array}{c}\text { \% Tiempo } \\
\text { dedicado } \\
\text { al trabajo } \\
\text { pagado }\end{array}$ & $\begin{array}{c}\text { \% Tiempo } \\
\text { dedicado } \\
\text { al trabajo } \\
\text { en casa }\end{array}$ & $\begin{array}{c}\% \\
\text { Tiempo } \\
\text { dedicado } \\
\text { al ocio }\end{array}$ & $\begin{array}{c}\text { Miembros del } \\
\text { hogar } \\
\text { (promedio de } \\
\text { individuos) }\end{array}$ & $\begin{array}{c}\text { Tasa de } \\
\text { consumo } \\
\text { de agua por } \\
\text { tipología } \\
\text { (m3/año) }\end{array}$ & $\begin{array}{l}\text { Tasa generación } \\
\text { de residuos no } \\
\text { aprovechables } \\
\text { (kg/año) }\end{array}$ & $\begin{array}{c}\text { Territorio } \\
\text { utilizado } \\
\text { (m2) }\end{array}$ & $\begin{array}{c}\text { Cantidad } \\
\text { de } \\
\text { producto } \\
\text { por unidad } \\
\text { de área } \\
(\mathrm{kg} / \mathrm{m} 2)\end{array}$ \\
\hline Huertos & $27,50 \%$ & $23,96 \%$ & $13,89 \%$ & 4,50 & 453,33 & 482,09 & 333,33 & 0,24 \\
\hline Negocio & $41,67 \%$ & $23,33 \%$ & $10,00 \%$ & 3,86 & 128,74 & 938,17 & 1376,00 & 0,00 \\
\hline $\begin{array}{l}\text { Negocio, } \\
\text { crianza y } \\
\text { huertos }\end{array}$ & $22,22 \%$ & $40,83 \%$ & $10,42 \%$ & 4,00 & 462,22 & 932,97 & 1142,00 & 0,03 \\
\hline $\begin{array}{l}\text { Negocio, } \\
\text { huertos } \\
\text { y/o } \\
\text { agricultura }\end{array}$ & $36,46 \%$ & $45,83 \%$ & $10,42 \%$ & 4,75 & 211,11 & 143,92 & 275,00 & 0,97 \\
\hline $\begin{array}{l}\text { Crianza de } \\
\text { animales }\end{array}$ & $30,56 \%$ & $28,47 \%$ & $27,78 \%$ & 4,40 & 408,00 & 427,64 & 1060,00 & 0,03 \\
\hline
\end{tabular}

La Figura 3 muestra la diversidad de actividades dentro del territorio, cuyos valores de fondos y flujos de tiempo y tierra se encuentran representados en colores. El gráfico muestra la relación de flujo/fondo (tasa de consumo de agua, tasa de generación de residuos) y el uso de la tierra (producto de unidad de área, área utilizada por tipología); estos valores están además asociados al número de miembros promedio por cada hogar. 


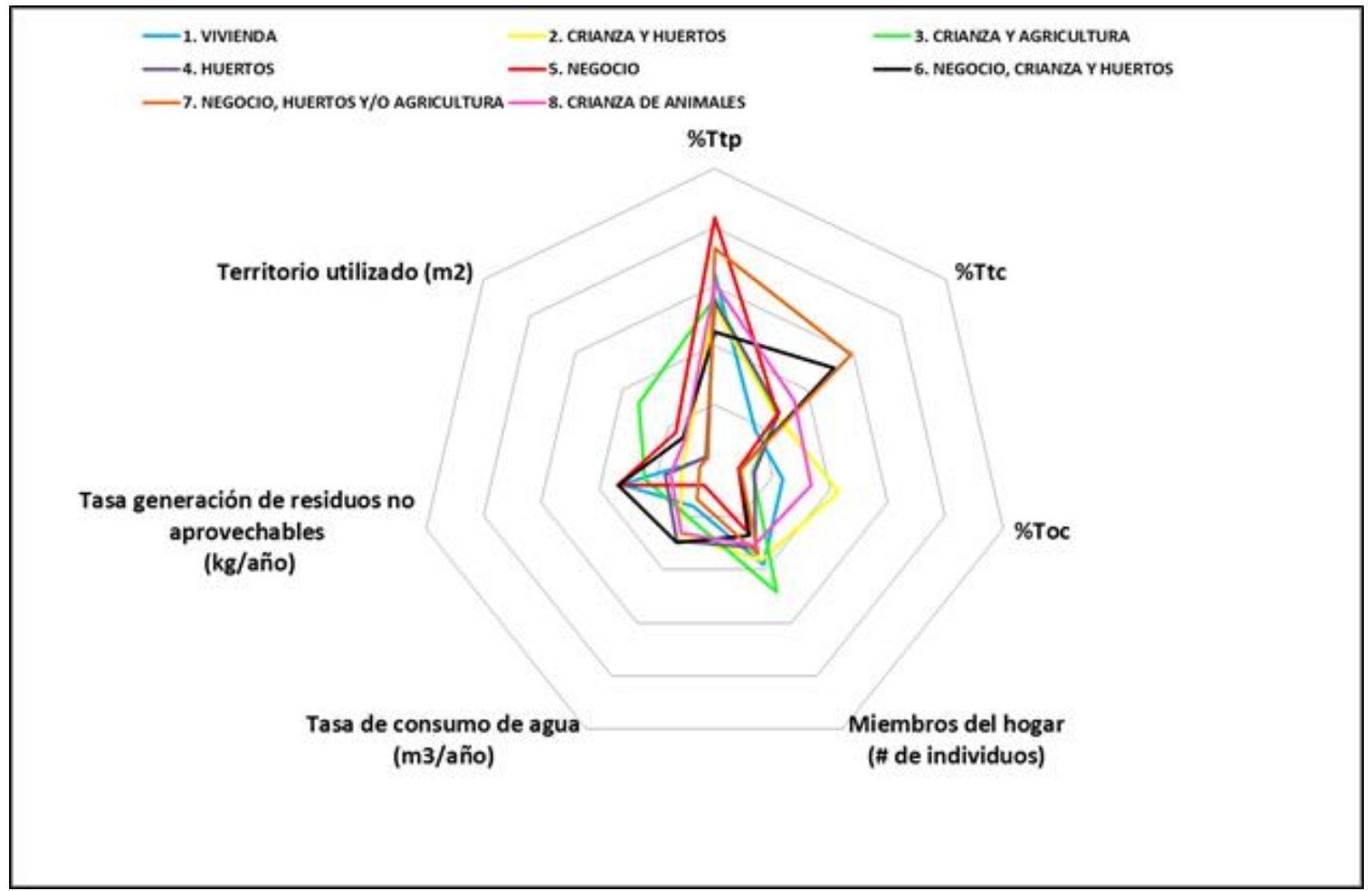

Figura 3. Gráfico radar de las tipologías existentes en relación con las encuestas realizadas. Fuente: Elaboración propia en base a los datos normalizados de la tabla 4.

Transformaciones metabólicas por la interacción urbano-rural

Una de las fuentes hídricas del sector Sangolquí, es el río Pita, que se origina por deshielo del volcán Cotopaxi, y por la unión de riachuelos, acequias y quebradas. Algunas acequias y quebradas han sido rellenadas y ahora se utilizan como vías de acceso al transporte público. El clima ha cambiado en los últimos años por lo que la población ha tenido que explorar nuevas formas de riego de sus cultivos. La tipología con mayor consumo de agua es la de Negocio, crianza de animales y huertos, cuya cuota es de aproximadamente 462,22 m3/año de agua consumida. Los negocios (tipología 4E) consumen alrededor de 128,74 m3/año y en las viviendas (tipología 1) 252,44 m3/año. Las figuras 4A, 4B, 4C y 4D muestran los usos de agua para las distintas tipologías.

Alfa, Revista de Investigación en Ciencias Agronómicas y Veterinarias Vol. 5, N Nro. 13, Enero - abril 2021 
Tipologías acerca del uso del agua (figura 4A, 4B, 4C y 4D).

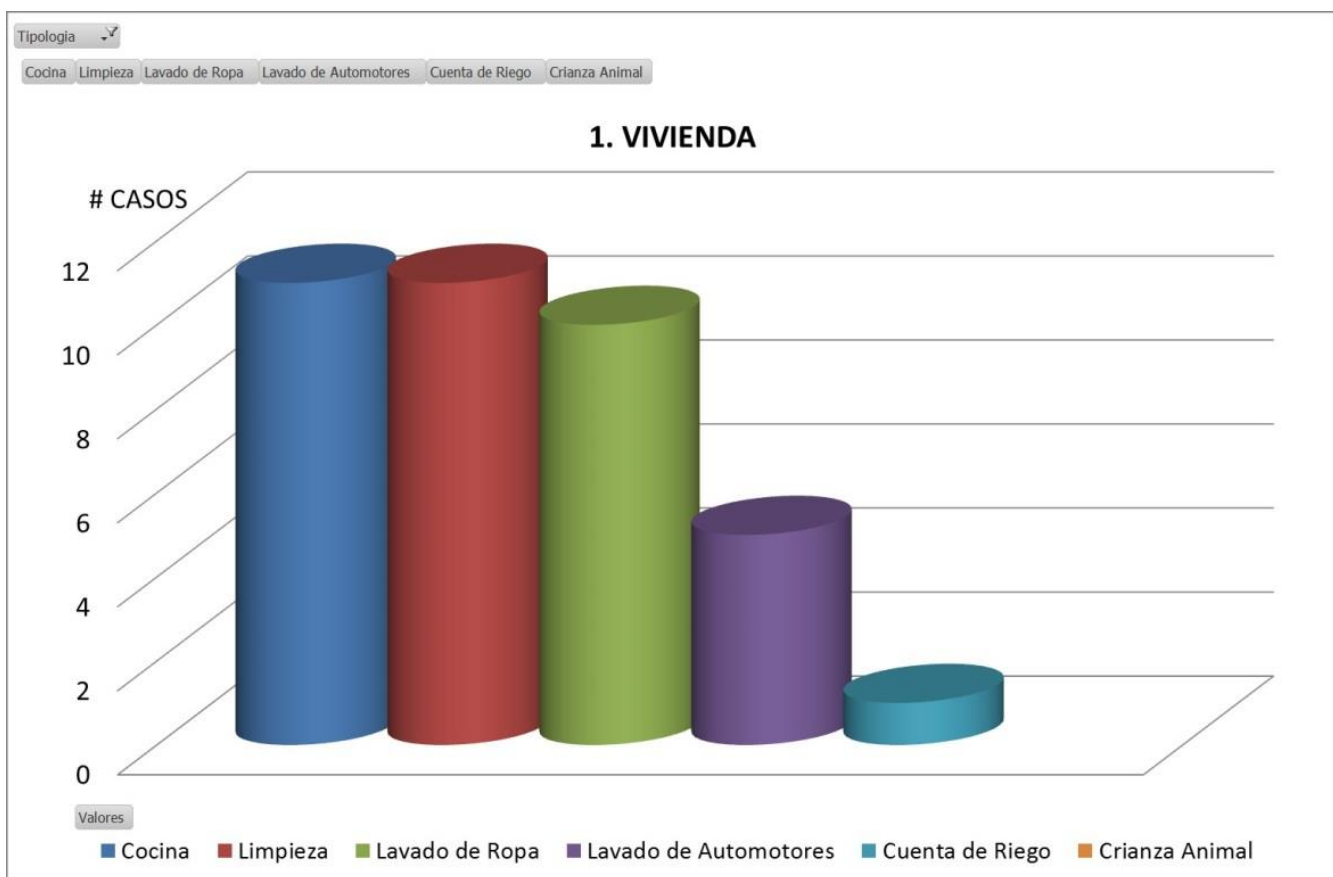

Figura 4A. Tipología vivienda.

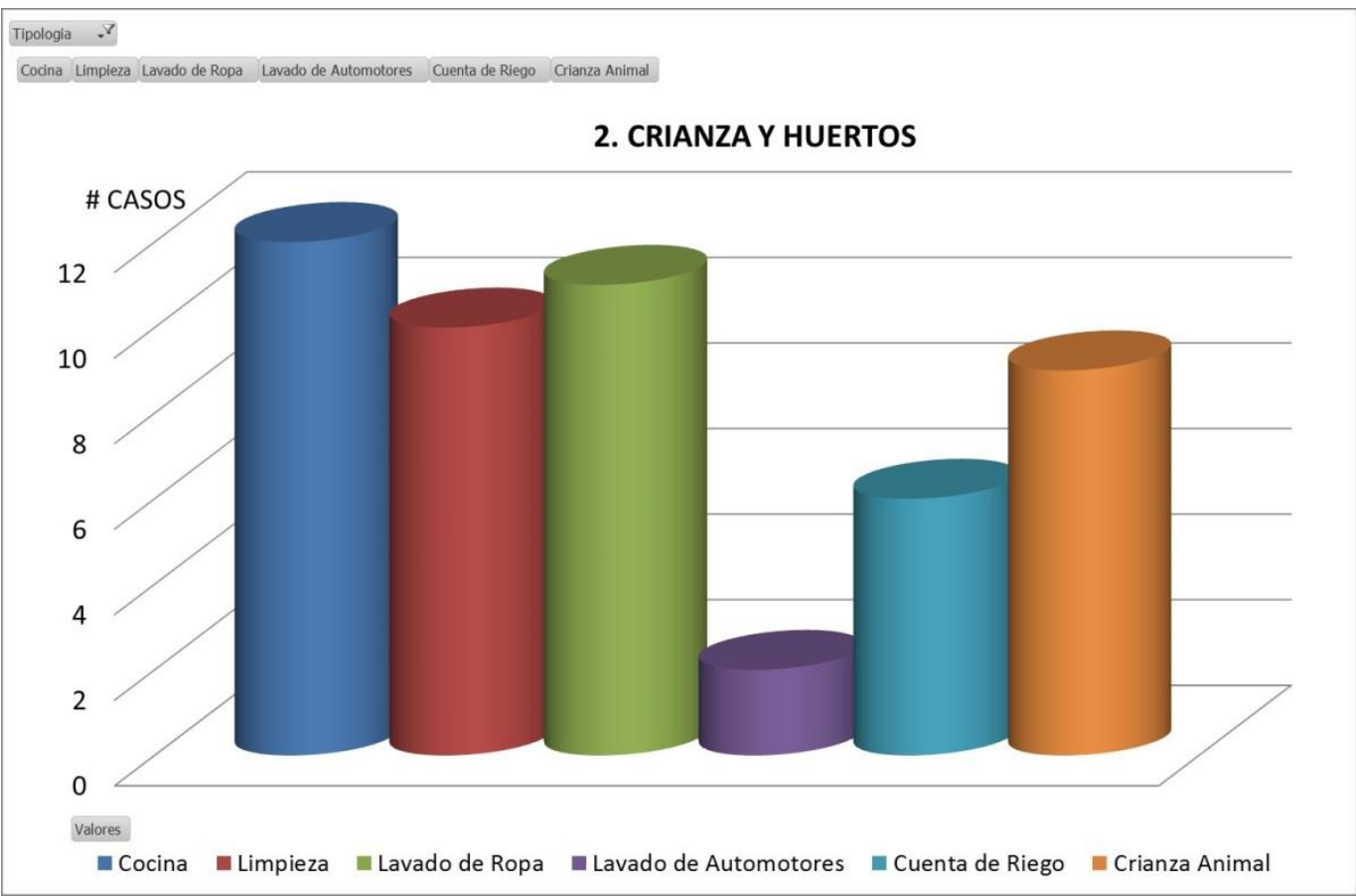

Figura 4B. Tipología crianza y huertos. (Fuente: Elaborado por el Ing. Carlos Castillo, a partir de los datos obtenidos en las encuestas realizadas al sector rural.

Alfa, Revista de Investigación en Ciencias Agronómicas y Veterinarias Vol. 5, JNro. 13, Enero - abril 2021 


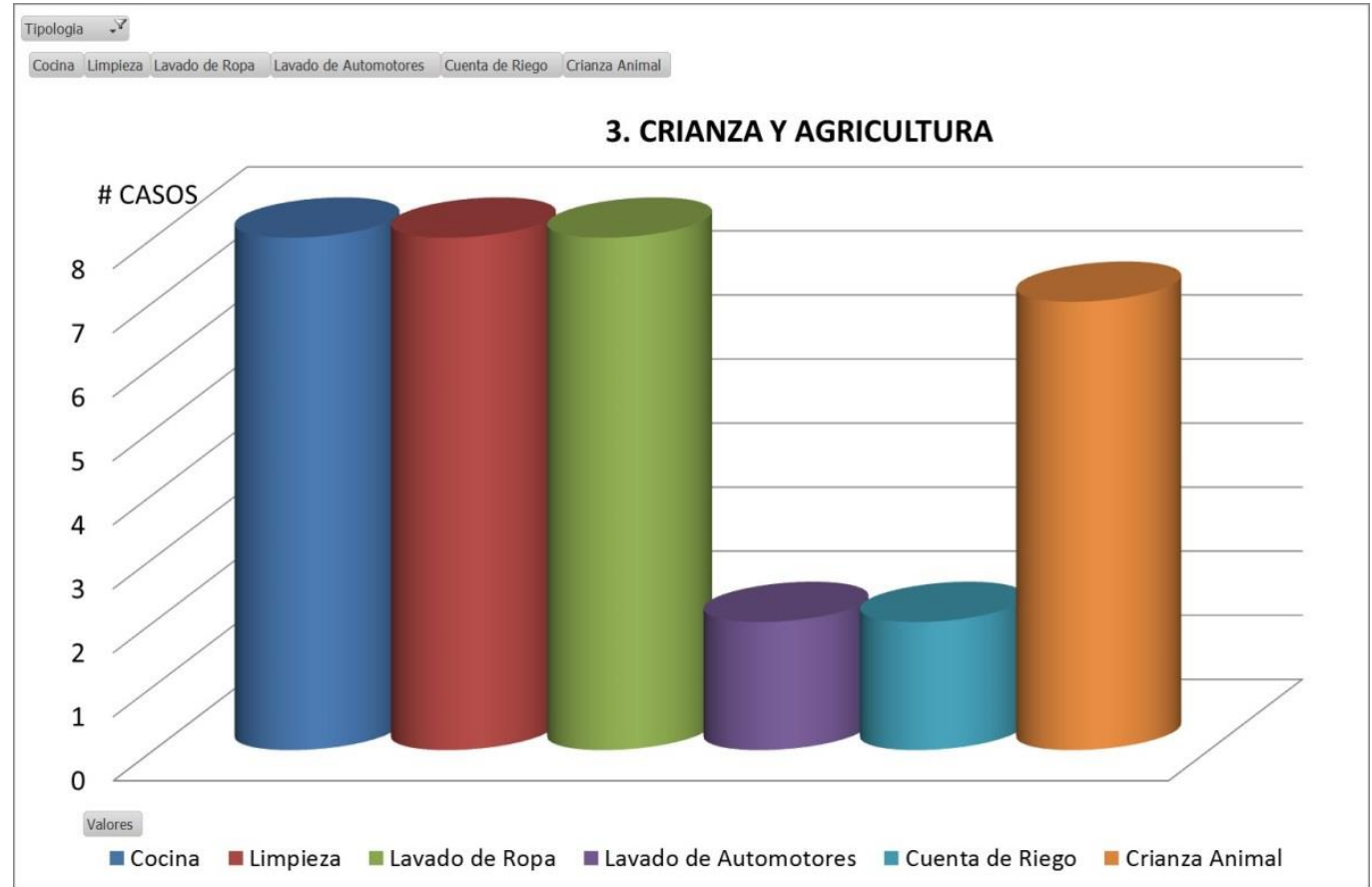

Figura 4C. Tipología crianza y agricultura.

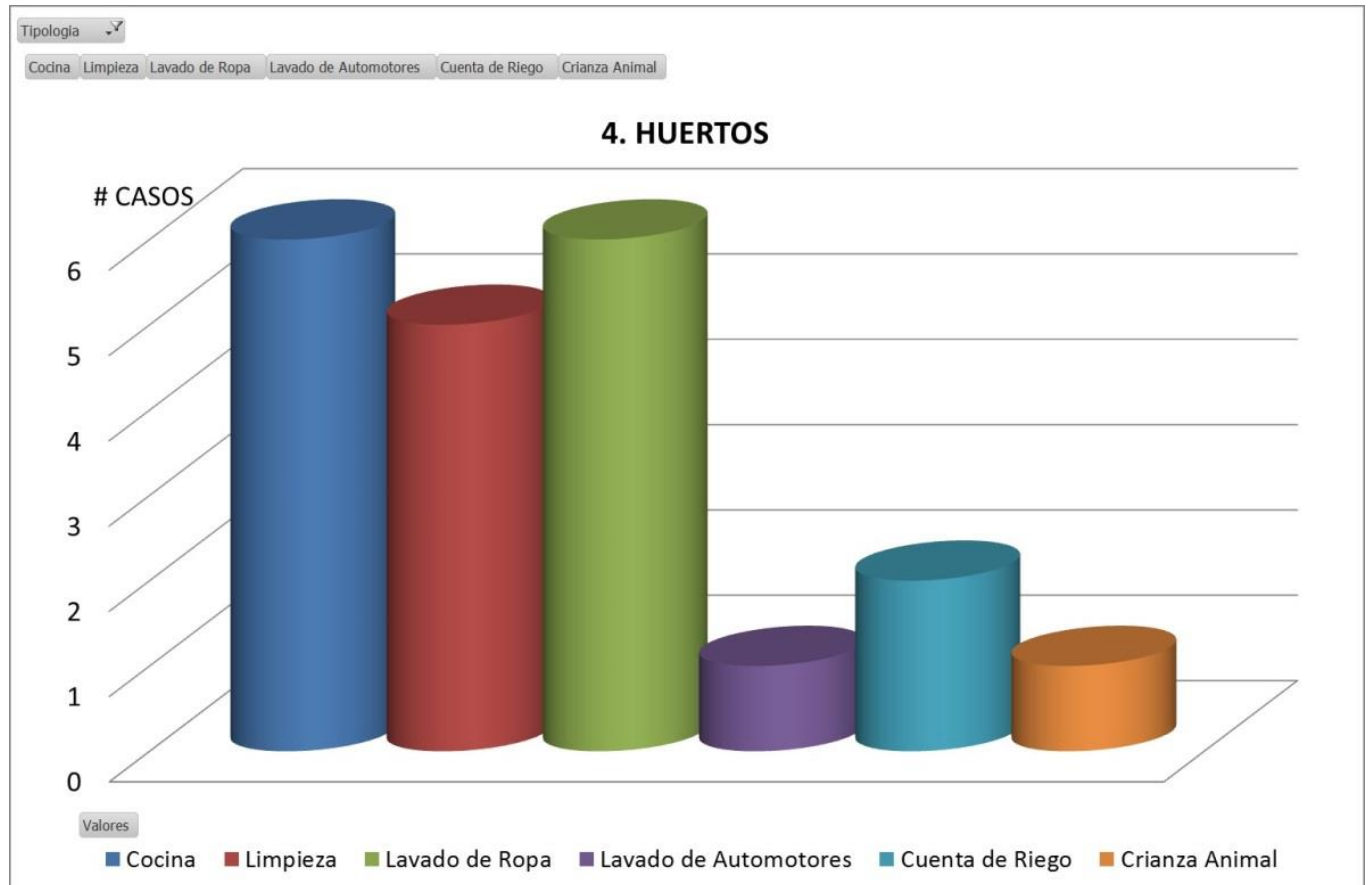

Figura 4D. Tipología huertos. (Fuente: Elaborado por el Ing. Carlos Castillo, a partir de los datos obtenidos en las encuestas realizadas al sector rural.

Alfa, Revista de Investigación en Ciencias Agronómicas y Veterinarias Vol. 5, Nro. 13, Enero - abril 2021 


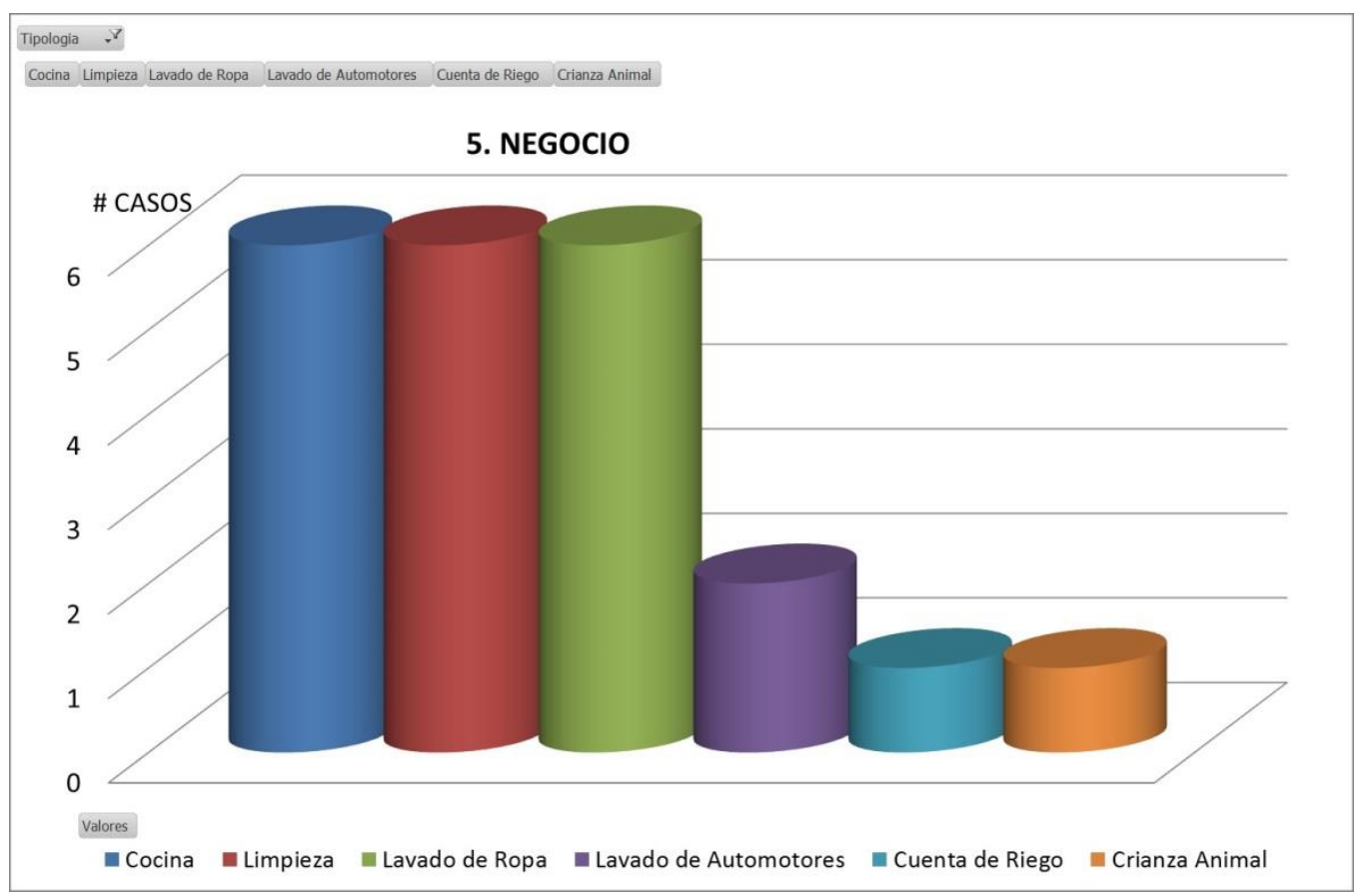

Figura 4E. Tipología negocio.

En cuanto a la generación de residuos, los negocios son los que producen la mayor cantidad, alrededor de 938,17 kg/año. Los empaques de los productos son los residuos más voluminosos y pueden ser reutilizables, reciclables o desechables.

Los negocios, crianza de animales y huertos son la segunda tipología con más producción de residuos. Le sigue las viviendas, que generan alrededor de 897,66 kg/año de residuos sólidos, cuya disposición final es en rellenos sanitarios, considerando que no se realiza la clasificación en la fuente y por lo general los residuos van mezclados. En algunos casos, se reportó la incineración a cielo abierto de papel y plástico, materiales que al combustionarse emanan gases tóxicos (dioxinas y furanos únicamente los plásticos) que pueden afectar la salud de las personas.
Dentro de las prácticas rurales, el recurso hídrico y la disposición de los residuos son aspectos muy importantes. El labrado de tierra de uso agrícola y para crianza de animales depende directamente de la disponibilidad del agua en donde se conforma un ciclo de recirculación de materiales.

Las ordenanzas que derivan del PDOT de Rumiñahui 2012-2015 y subsiguiente, establecen obligaciones de extensión de servicios de agua potable, alcantarillado y recolección de residuos a todo el territorio. Esta expansión hacia zonas rurales y la desvinculación social con la naturaleza promueven la contaminación del entorno sin control político ni normativo.

La productividad de los predios se aprecia en la Figura 5. 


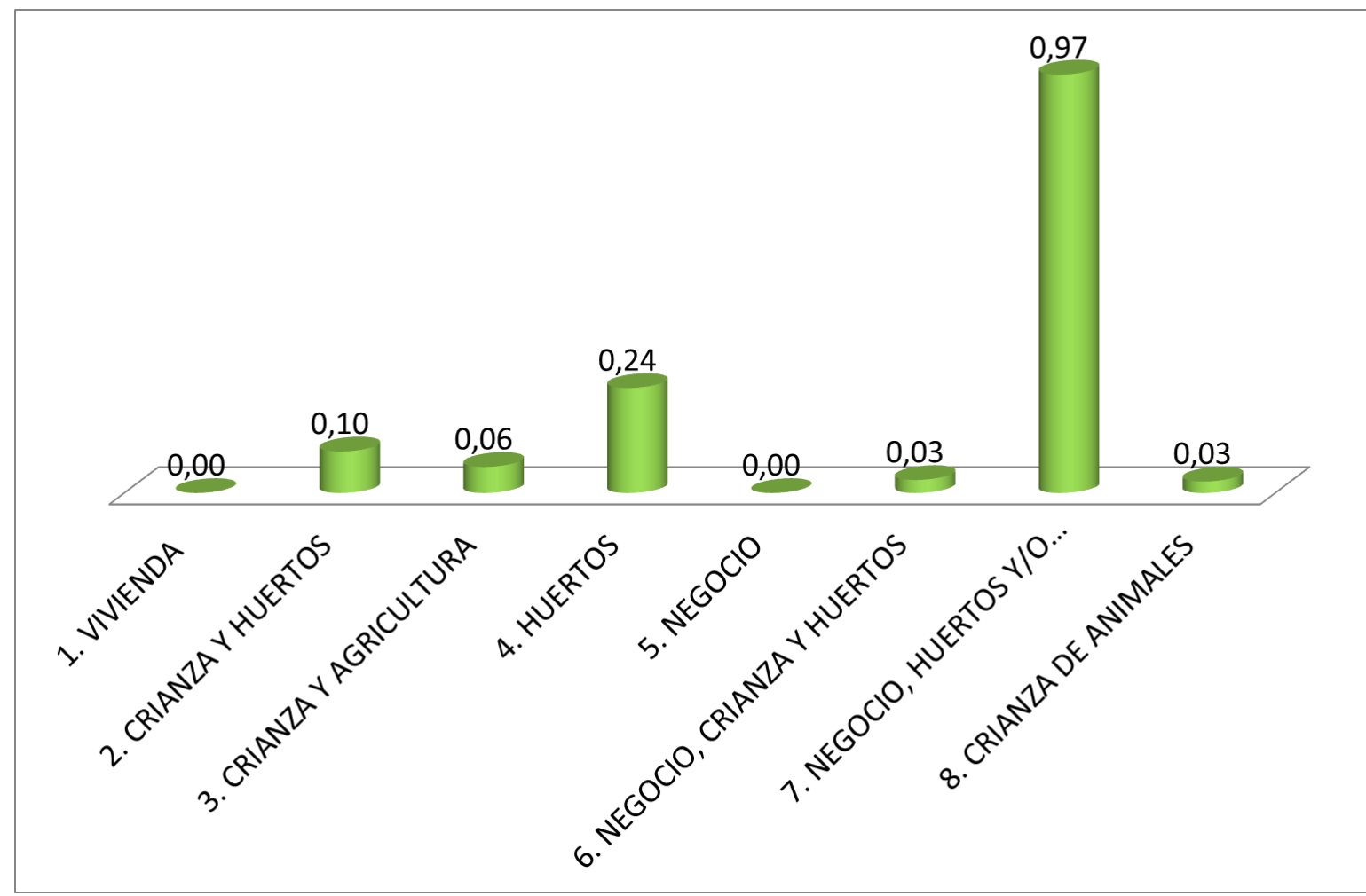

Figura 5. Productividad por metro cuadrado de terreno.

Fue difícil estimar el valor exacto de venta del producto porque los valores variaban de persona a persona. En el caso de cultivos extensivos de maíz y papa, la venta promedio puede oscilar entre los 1000 y 1500 dólares al año que dependen del clima, salud del cultivo y precio del mercado. Esta producción asegura un ingreso a un hogar de acuerdo al número de miembros de familia que varía desde 1 a 12, en dónde el promedio de personas adultas que trabaja va desde 1 a 4 .
El $80 \%$ de los productos del total de tipologías son obtenidos únicamente para consumo propio del hogar y de sus familiares más cercanos, según lo mencionado en las encuestas.

En el caso de los huertos el agua se toma de la red municipal y esto implica un costo elevado para cubrir los gastos por la manutención de un huerto de autosustento (Figura 6). 


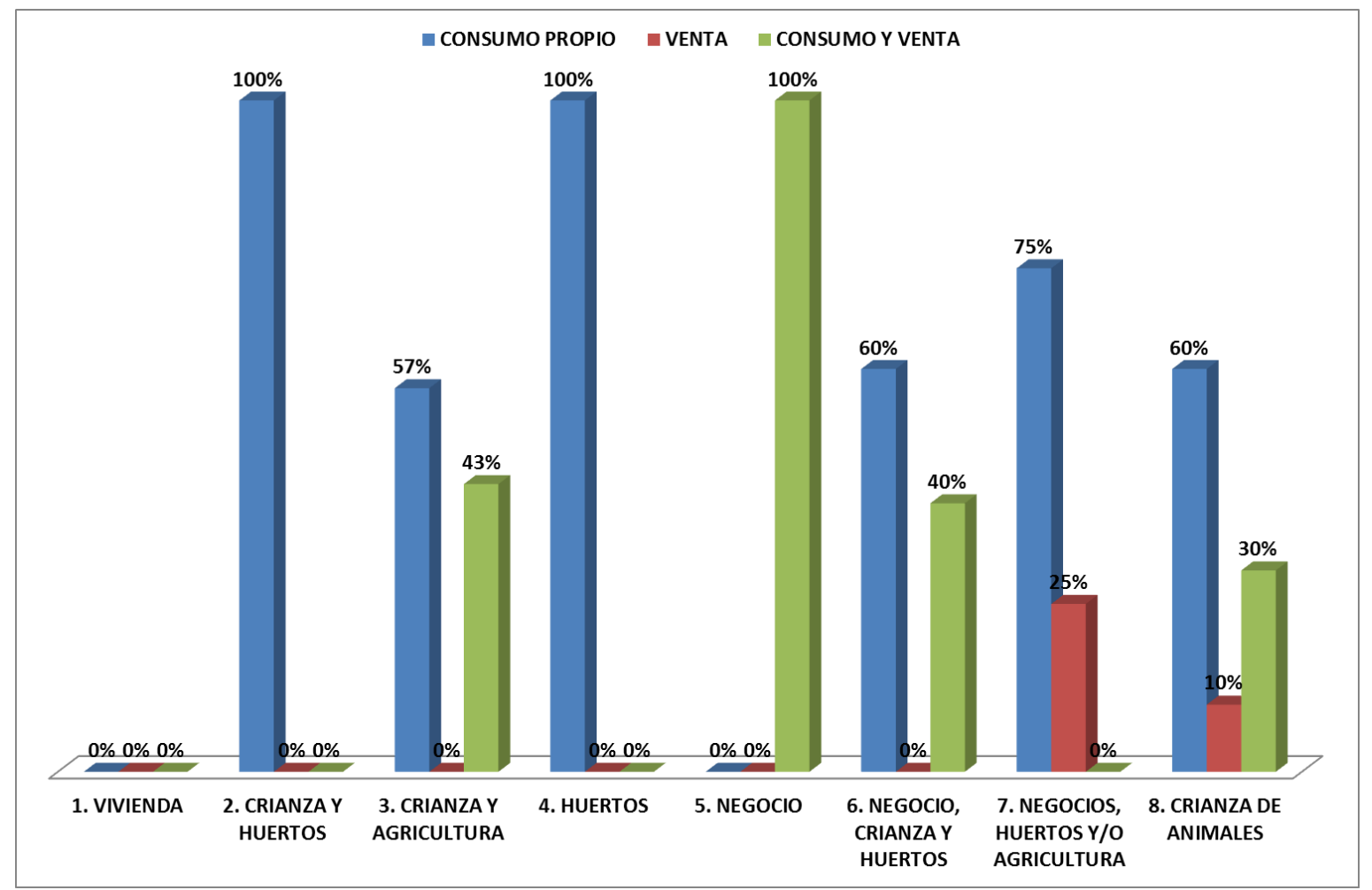

Figura 6. Uso de los productos obtenidos.

Las actividades que se realizan en los sectores rurales se entrelazan con las urbanas debido a que existe interacción entre los habitantes. El proceso de urbanización que ha tenido la parroquia genera dinámicas de repulsión y atracción de la población hacia el territorio. Este fenómeno ocasiona conflictos socioambientales entre la población ruralurbana que sumado al metabolismo industrial contribuye al impacto del ambiente.

Existen dos industrias principales en el Loreto (parroquia analizada) una dedicada a la extracción de material pétreos (contaminación con sólidos al cauce del río) y la segunda a la agroindustria de cultivo de rosas (contaminación por pesticidas, olores que afectan la calidad del aire y suelo).

La tabla 5 y Figura 7 muestra las actividades industriales de Sangolquí y su consumo de agua y generación de residuos en el territorio. 
Tabla 5. Datos fondos/flujos de tipologías industriales.

\begin{tabular}{lccc}
\hline \multicolumn{1}{c}{ Tipología } & $\begin{array}{c}\text { Tasa de consumo de } \\
\text { agua (m3/año) }\end{array}$ & $\begin{array}{c}\text { Tasa generación de residuos no } \\
\text { aprovechables (kg/año) }\end{array}$ & $\begin{array}{c}\text { Territorio } \\
\text { utilizado (m²) }\end{array}$ \\
\hline 1. Agroindustrial & 24348,00 & 5324000,00 & 500822,195 \\
2. Alimenticia & 5928,00 & 48000,00 & 2100 \\
3. Manufactura & 42432,00 & 242160,00 & 28758,74 \\
4. Metalmecánica & 4674,00 & 15690,00 & 11038,5 \\
5. Bodega/Servicio & 353,00 & 26115 & 3518,49 \\
6. Textil & 180000,00 & 360000,00 & 230000 \\
\hline
\end{tabular}

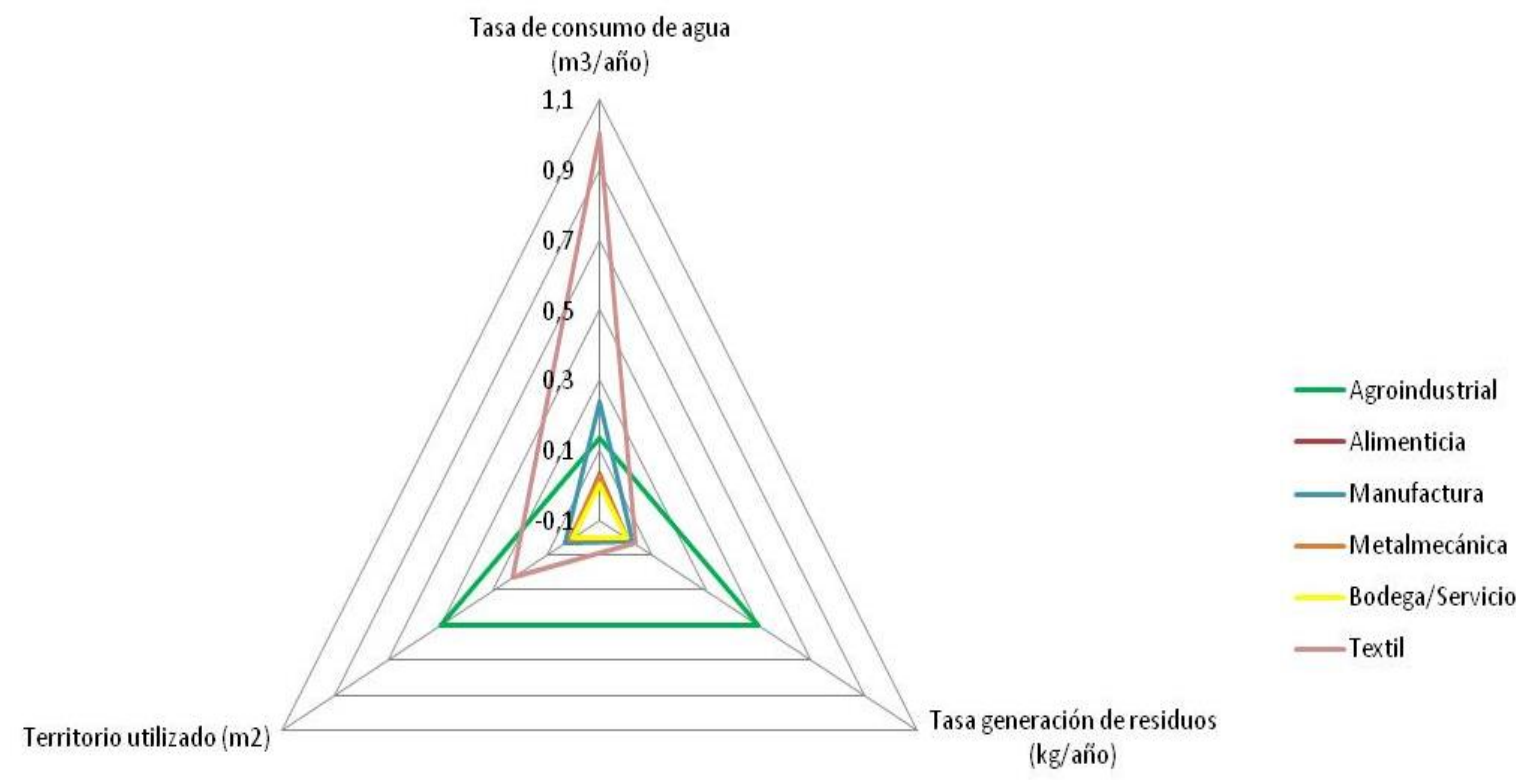

Figura 7. Gráfico tipo radar de las tipologías industriales.

DISCUSIÓN Las personas que realizan sus actividades

Las nuevas ruralidades constituyen el resultado de esta mezcla de diversas actividades que contribuyen a la economía del hogar (agricultura y crianza de animales) y el empleo fuera del mismo. Se observó que la diversidad de tipologías descritas, se da por esta mezcla del uso del suelo que genera matices urbanos en territorios rurales $\mathrm{y}$ periurbanos. laborales fuera de casa $(17,19 \%$ tipología de vivienda únicamente), no pueden dedicar su tiempo y espacio a la agricultura y crianza de animales. El costo de vida de la vivienda y necesidad de salario fijo hacen que las actividades fuera de casa representen el mayor tiempo de las personas y que la cultura ligada a la agricultura y crianza de animales disminuya en porcentaje entre la población. 
Existen diferencias en cuanto a la estimación de las horas que fueron proporcionadas por los encuestados. No se registraron las horas de pernoctación de cada uno, ni actividades de las tareas de hijos o compras de insumos.

El metabolismo del territorio cambia al tener un aumento de la densidad poblacional; este aspecto incrementa también el uso de recursos como el agua y la disposición de residuos y desechos líquidos. La agrupación de actividades (pluriactividad) genera un incremento de la producción de residuos sólidos y consumo de agua para las distintas ocupaciones. La atención de los negocios, en su mayoría tiendas de abarrotes, representa el $50 \%$ del tiempo de las personas, que fue la actividad económica más frecuente entre los encuestados.

Luego del análisis de radar se puede describir que para el caso número de miembros que viven en el hogar, la tasa de consumo de agua y la generación de residuos no es directamente proporcional. La tipología con el mayor número de individuos en el hogar es la tres "crianza y huertos"; sin embargo, esta tipología no consume tanta agua ni genera una cantidad considerable de residuos no aprovechables. El consumo de agua se asocia principalmente a las actividades relacionadas a la agricultura y crianza de animales. A pesar de que el dato fue proporcionado por el consumo de agua potable del servicio municipal; cabe mencionar que algunas personas encuestadas mencionaron que consumían agua de una vertiente (dato no estimado durante la investigación).

Las tipologías 1, 5 y 6 son muy similares en generación de residuos y se parecen a aquellas que hay a nivel urbano. Por un lado, los terrenos en el área de análisis son de naturaleza agrícola y de potreros de hacienda, por lo que la mayoría han servido en la actualidad con ese mismo fin, agricultura y crianza de animales menores y mayores. Por otro lado, las tipologías más relacionadas con la actividad agrícola son las que menos residuos sólidos producen ya que en su mayoría son orgánicos que los utilizan los pobladores como abono de sus propios terrenos o alimento de los animales menores: conejos, pollos, porcinos y terneros.

Las descargas líquidas afectan directamente al componente agua, es decir ya sea que descarguen al sistema de alcantarillado o mantengan conexiones directas a fuentes hídricas como ríos o quebradas; estas descargas sin un tratamiento previo disminuyen significativamente la calidad del agua. Así, se contamina el recurso que una vez fue la fuente de agua utilizada para el riego de cultivos y para la crianza de animales. El sistema actual de uso de agua, muchas veces, interrumpe el ciclo de nutrientes y puede constituir un riesgo para la salud en cuanto a la transmisión de enfermedades en los países en vía de desarrollo (27).

El metabolismo urbano y el industrial afectan a la población rural de distintas formas ya que modifica la forma de vida $y$ calidad ambiental del entorno. El cambio de la cultura agrícola original del territorio analizado y desplazamiento humano a zonas periurbanas generan una transformación del metabolismo del territorio. Este aspecto condiciona el uso de recursos naturales como el agua $y$ el suelo que provocan una degradación ambiental.

Hay tres principales aspectos que desencadena conflictos: la interacción urbano rural en el uso del suelo, la interacción 
urbano-rural asociada al uso del agua y la interacción entre el metabolismo industrial versus los otros dos (rural y urbano). En la primera situación, interacción urbano-rural, existen algunos descontentos sobre la crianza de animales y la agricultura del sector. Algunos de los encuestados exigen su prohibición. Esto puede deberse a la expectativa distinta y falta de compatibilidad que tienen las personas con las actividades que actualmente se realizan en este sector periurbano (olores que genera la crianza de animales) $(28,29)$.

A pesar de que la urbanización y constante expansión de la mancha urbana hacia las afueras es aceptada por los residentes, no cabe duda que esta dinámica puede, en algún punto, destruir el capital social presente de la parroquia y fomentar el individualismo y cambio del estilo de vida (30). Por otro lado, no existe la percepción de que la contaminación de fuentes hídricas sea por las actividades urbanas o rurales; sino que, solo se atribuye a las industrias como culpables de este impacto.

El conflicto en la segunda interacción (industria vs. Ambos sectores) se debe al metabolismo acelerado de estas dos actividades que llega a causar molestias en la población aledaña; empero de esta situación, alrededor de la industria florícola existe una fluctuante migración de personas de la costa y Colombia que se dedican, eventualmente, a la cosecha y post cosecha de las rosas. Esta migración contribuye a los ingresos de la población de Loreto y genera aumento de comercio y ocupación de viviendas en arriendo.

Las actividades industriales deben, por normativa, mantener un control sobre las actividades; sobretodo, por las descargas a fuentes hídricas y generación de residuos. La globalización del agro y la tecnología asociada a él, intensifica la actividad y la traslada a nuevos lugares en donde se acentúan las interacciones entre lo rural y lo urbano $(23,31,32,11)$.

Cabe mencionar que, en su mayoría, las industrias realizan un tratamiento previo a la disposición final (33). Toda actividad productiva genera un impacto al ambiente y a la sociedad. Estas prácticas afectan a la población urbana y también a la rural, puesto que la gente que viven en zonas alejadas de la mancha urbana busca lugares más tranquilos $\mathrm{y}$ alejados para no verse afectados por estos conflictos y externalidades negativas ambientales (34).

Durante la investigación se tuvieron dos hallazgos importantes, uno relacionado a que los pobladores mostraron una necesidad de cambio de sus actividades y costumbres a las urbanas (convertirse en urbanos). El segundo corresponde a los conflictos por la competencia en el uso del recurso o desplazamiento de las actividades relacionadas con la agricultura por el crecimiento urbano.

La ocupación desordenada del suelo por la población urbana, genera interacción entre los espacios que sufre desplazamiento de actividades asociadas al cultivo y ganadería. La dificultad de establecer límites entre los territorios urbanos y rurales conlleva a la creación de matices ("continuum") urbanos en las zonas periféricas de las ciudades, áreas de influencia inmediata, rurbanas o periurbanas $(35,36)$.

Es importante el desarrollo de ordenanzas y normativas de ordenamiento territorial en la zona para mejorar la capacidad de control y regulación del uso del 
suelo y otros recursos naturales por parte de los pobladores (Bernal, 2009). El estilo de vida de las personas varía conforme a sus necesidades y el territorio de igual manera. Llegará posiblemente, un punto en el que el terreno destinado a los cultivos y la crianza se convierta en infraestructura urbana.

El estudio de la situación metabólica del sector de Sangolquí puede servir de referencia para otros territorios que han sufrido una transformación en el uso del suelo en la región andina. Los flujos de materiales y energía varían de acuerdo a muchos factores, entre los cuales el demográfico es el más importante y que amerita ser estudiado a profundidad. Se requiere, sin duda, realizar más estudios profundos del tema para aminorar los efectos que tienen las actividades productivas sobre el recurso hídrico.

\section{CONCLUSIONES}

Una vez evaluado los resultados se concluye que las tipologías de actividades ayudan al análisis metabólico del territorio; además que los recursos naturales en un territorio son limitados y son susceptibles de competencia en la población por lo que su acceso si el capital social se ve afectado por el deterioro del ambiente, definitivamente esta situación genera un conflicto. Aunado a esto se tiene que el metabolismo rural de la parroquia de Sangolquí está restringido por el uso del suelo, crecimiento urbano, aumento de actividades industriales relacionadas a la agroindustria y la extracción de materiales pétreos; por lo que las actividades industriales impactan al ambiente y a los pobladores de la zona; estas dos actividades industriales, generan un ingreso $y$ contribuyen con plazas de trabajo para el sector.

Por ende se entiende que las nuevas ruralidades nacen de la transformación de un territorio con un uso distinto al original (agricultura y ganadería a urbanizado); a la expansión de la industria conlleva la ocupación de nuevos territorios, urbanización y comercio asociado, obteniendo que la vinculación entre los procesos migratorios y la industria seguirá dándose, sobretodo, en las zonas periféricas de las ciudades, para que las decisiones administrativas aceleran, en muchos casos, el aparecimiento de conflictos socioambientales.

\section{REFERENCIAS}

1. Swyngedouw E. Metabolic Urbanization: In The Nature of Cities. Urban Political Ecology and the Politics of Urban Metabolism. Routledge: Nueva York; 2006. 21-40.

2. Seto K, Fragkias M, Güneralp B, Reilly M. A Meta-Analysis of Global Urban Land Expansion. Plos One. 2011 6(8): 1-9. [Consultado 2020 Dic 20].

3. Carvajal N. Nuevas Dinámicas UrbanoRurales en Bogotá y Soacha. Revista Eutopía [Internet]. 2012; (3): 51-66. [Consultado 2020 Dic 20]. Disponible en: http://revistas.flacsoandes.edu.ec/eutopia/a rticle/view/1022.

4. Schteingart M. Expansión urbana, conflictos sociales y deterioro ambiental en la ciudad de México, El caso del Ajusco. Estudios Demográficos y Urbanos, [Internet]. 1987; 2(3): 449-477. [Consultado 2020 Dic 20]. Disponible en: http://www.jstor.org/stable/40310378.

5. Linck T. El campo en la ciudad: reflexiones en torno a las ruralidades emergente. Ponencia presentada en el Seminario sobre políticas alternativas hacia las áreas rurales 
del D.F. para discutir las grandes orientaciones discutidas en Europa. 2001. [Consultado 2020 Dic 20]. Disponible en: http://www.pa.gob.mx/publica/cd_estudios /Paginas/autores/linck\%20thierry\%20el\%2 0campo\%20en\%20la\%20ciudad.pdf.

6. Martinez Alier J. El Ecologismo de los Pobres: Conflictos ecológicos por extracción de recursos y por producción de residuos. Maryland: Icaria Editorial; 2004.

7. Heynen N, Kaika M, Swingedouw E. Urban Political Ecology. En The Nature of Cities. Urban Political Ecology and the Politics of Urban Metabolism. Routledge: Nueva York; 2006. 1-20.

8. Zimmer A. Urban Political Ecology: Theoretical Concepts, Challenges and Future Directions. Erkunde. 2010; 64(4): 343-354.

9. ONU- Hábitat. Estado de las ciudades de América Latina y el Caribe. Programa de las Naciones Unidas para los Asentamientos Humanos. Río de Janeiro, Brasil. 208 pp. 2010.

10. Presidencia de la República del Ecuador. América Latina es la región más urbanizada del planeta. 2020. Disponible en: https://www.presidencia.gob.ec/americalatina-es-la-region-mas-urbanizada-delplaneta/

11. Llambí L. Procesos de transformación de los territorios rurales latinoamericanos: los retos de la interdisciplinariedad". Revista Eutopía, [Internet]. 2012; (3): 117-134. [Consultado 2020 Dic 20]. Disponible en: http://repositorio.flacsoandes.edu.ec/bitstre am/10469/5490/1/RFLACSO-Eu3-07Llambi.pdf.

12. Sabatini F. Chile: conflictos ambientales locales y profundización democrática. Ecología Política. 1997; (13): 51-69.

13. Mancheno D. y Muñoz M. Quito ¿Una ciudad diversa o especializada? Questiones Urbano Regionales. Instituto de la CiudadDistrito Metropolitano de Quito, [Internet]. 2013; 1:161-201. Disponible en: http://repositorio.flacsoandes.edu.ec/bitstre am/10469/6460/3/REXTN-QUR3-09Mancheno.pdf.

14. Martínez Alier J. Ecología política del extractivismo y justicia ambiental. Dossier Revista UNAM [Internet]. 2015; 3(7): 57-73. [Consultado 2020 Dic 20]. Disponible en: http://dx.doi.org/10.22201/ceiich.2448570 5e.2015.7.52384.

15. De la Cruz Carrillo FE. Conflictos socioambientales y acción colectiva contenciosa en el Área Metropolitana de Monterrey, Nuevo León, México (2008-2018). Agua Y Territorio [Internet]. 2020; (16): 35-46. [Consultado 2020 Dic 20]. Disponible en: https://doi.org/10.17561/at.16.4906.

16. Municipio de Rumiñahui. Atlas del Plan de Desarrollo y Ordenamiento Territorio 2012-2025. 2012.

17. Dirección de Protección Ambiental del GADMUR. Noticias de Rumiñahui. Gestión ambiental. 2015. Disponible en: http://www.ruminahui.gob.ec/rumi3/direcc ion-de-proteccion-ambiental-del-gadmur/

18. Censo de Población y Vivienda realizado por el Instituto Nacional de Estadísticas y Censos (INEC) del 2010.

19. INEC. Información Cartográfica. Cartografía digital 2010. Versión 2010. 2017. Disponible en: https://www.ecuadorencifras.gob.ec/catego ry/cartografia-2/

20. Giampietro $M$ y Kozo $M$. The Biofuel Delusion: The fallacy of large-scale agrobiofuel production. Earthscan, London. Appendix 1: Basic Theoretical Concepts behind the Analysis of Societal Metabolism. 2009.

21. Giampietro $M$, Kozo $M$. The Biofuel Delusion: The fallacy of large-scale agrobiofuel production. Earthscan, London. Chapter 4: Pattern of Societal Metabolism across Levels: A Crash Course in Bioeconomics. 2009. 
22. Castan Broto V, Allen A, Rapoport E. Interdisciplinary Perspectives on Urban Metabolism. Journal Industrial Ecology. 2012; 16(6): 851-86.

23. Ariza-Montobbio $P$, Farrel $K$, Gamboa G, Ramos J. Integrating energy and land-use planning: socio-metabolic profiles along the rural-urban continuum in Catalonia (Spain). Environmental Development and Sustainability, Springer. 2014; 16. Pp. 1-34.

24. Gomiero T, Giampietro M. Multiple-Scale Integrated Analysis of Farming Systems: The Thuong Lo Commune (Vietnamese Uplands) Case Study. Population and Environment. 2001; 22 (3): 315-352.

25. Sautu R, Boniolo P, Dalle P, Elbert R. Manual de Metodología: construcción del Marco Teórico, formulación de los objetivos y elección de la metodología. Buenos Aires: Consejo Latinoamericano de Ciencias Sociales CLACSO; 2005, 140-144.

26. Rosas-Baños M. Nueva Ruralidad desde dos visiones de progreso rural $y$ sustentabilidad: Economía Ambiental y Economía Ecológica. Polis Revista Latinoamericana [Internet]. 2013; 12(34): 225-241. [Consultado 2020 Dic 20]. Disponible en: http://www.scielo.cl/pdf/polis/v12n34/art 12

27. Bernal Pedraza AY. Gestión del agua- una preocupación de las empresas ambientalmente responsables. Revista Universidad Y Empresa [Internet]. 2009; 12(19), 87-106. [Consultado 2020 Dic 20]. Disponible en: https://revistas.urosario.edu.co/index.php/e mpresa/article/view/1300
28. Tacoli C. Rural Urban Interactions: a guide to literature. Environment and Urbanization. 1998; 10(1): 1-20.

29. Tacoli $C$. The links between urban and rural development. Environment and Urbanization. 2003; 3-11.

30. Carrión F. La ciudad construida Urbanismo en América Latina. Facultad de Ciencias Sociales. Ecuador; 2001, 7-24.

31. González M. Identidades y conflictos en territorios de frontera rural-urbana. Revista Eutopía [Internet]. 2012; (3): 95-115. [Consultado 2020 Dic 20]. Disponible en: www.flacsoandes.edu.ec

32. Llambí L, Pérez E. Agenda para una nueva sociología rural latinoamericana. Cuadernos Des. Rural. 2007; 4 (59): 37-61.

33. Vilatuña E. Sistema de Gestión Integral de Residuos Sólidos en el cantón Rumiñahui. Tesis de Grado de la Maestría en Sistemas de Gestión Ambiental. Departamento de Ciencias de la Tierra ESPE; 2012, 1-145.

34. Martínez Alier J, Orta M, Silva JC. Análisis de conflictos ecológicos. ICTA, Universidad Autónoma de Barcelona; 2008, 1-19. Disponible en: www.deudaecologica.org/documentos/.../co nflictos_ecologicos_alier.doc.

35. Kingman E. Historia social urbana, espacios y flujos. Facultad de Ciencias Sociales- Flacso. Ecuador; 2009, 10-20.

36. Allen A. La interfase periurbana como escenario de cambio y acción hacia la sustentabilidad del desarrollo. Cuadernos del Cendes. 2002; 53, 1-15. 